\title{
POP Advertisement-An Out Reach for Sales Promotion
}

\author{
Jitender Chawla \\ (Assistant Professor, Department of Commerce, Dyal Singh College)
}

\begin{abstract}
The present article seek to find the traditional and modern ways of Point of Purchase tools and also finding the changes taking place over the time periods. The researchers also seeks to answer the tools which are suitable in Indian scanario.
\end{abstract}

\section{Introduction}

Over the past few years the increasing affluence, education and global exposure have changed the purchasing and shopping habits of the consumers. The growth of retail outlet in India has been driven by an increase in consumer spending which has grown at an average rate of 11.5 percent over the last decade. "More than 7,65;000 crores is spent annually by consumers through retail channels (POP Asia 2005). India ranks fifth in a list of 30 emerging retail market in the world, which clearly indicates that the retail opportunity in India is vast.Out of the 12 million retail outlets in India five million are in urban area" ${ }^{1}$. This fact contributesto the overall magnitude to the retail opportunity in India. Howeverthe current retail market at the global level is worth 180 billion dollars in which India's share is just 2 percent. It is growing at a healthy 8.5 percent on an annual basis and is likely to become 20 percent by 2010 end.

In the current scenario, the Point of Purchase (POP) advertisement is becoming one Of the fastest growing promotional media today. POP advertisement is the only media that the customer is exposed to when making a brand/product purchase decision in the place of purchase/store environment. These days both the brand makers and the retailers are increasingly spending their money in this medium because POP advertisement acts both as a strategic and a technical promotional medium and getting increased attention from brand advertisers as a means of building brand image as well as educating the customers as a means to stimulate impulse purchases.

According to advertising folklore two thirds of purchasing decisions are made at the point of sale of product. This is the only media environment in which advertisement does not depend on the consumer remembering the advertisement the following day or week, but recognizing it immediately. "The POP is an ideal time to communicate with the consumer because this is the time when many product or brand choice decisions are made, and this is the time and place when all elements of the sale (consumer, money and product) come together ${ }^{2}$. Because ofthe above reason, most brand advertisers and retailers are realising The Importance of the store environment which is taken to be the last chance to make a Diffrerence in the minds of shoppers through POP ad.

\section{Traditional and Modern Tools of POP Advertisement:}

Point of Purchase (POP) ad is an extremely flexible form of advertising. According to the Point of Purchase Advertising Institute (POPAl), POP performs four different functions in building sales viz., informing, reminding, persuading and merchandising within the place of purchase itself through both traditional as well as new media tool.

Traditional POP Advertisement Tools are:

Types of signs

Shelf ads

Plastic reproduction of products

Wire stand

Banners

Mirrors

Various types of product displays

Wall posters

Brochures
Plaques

Lights

Full line merchandisers

Mobiles

Mechanical mannequins

Checkout units

Dummy Packs

Floor advertisements

Leaflets

In the 1990s, the electronic interactive media has made POP ad to become very popular. As consumers enter the Supermarket or Drugstore or Mall, they are bombarded with various forms of new POP advertisements. 


\section{Modern POPAd Tool are:}

- Coupon dispensers

- Video ads on shopping carts

- Electronic signage

- Ad-supported with store radio and TV commercials

- Interactive POP material also meets the requirements of both retailers and consumers

\section{Privileges of POP Advertisement:}

Point of Purchase displays have been used since the retailer first opened their shops.

However, it has only been in the last two decades, that the POP has become a major component in most brand makers/manufacturers sales promotional plans. This investment in POP is justified in as much as ad material provides useful services for all participants in the marketing process (manufacturer, retailers and consumer). The following are the main reasons for the growing attention given to POP advertisements:

\section{For Manufacturer:}

- POP ad keeps the company's name, brand name before the consumer and reinforcesa brand image that has been previously established through advertising.

- It calls to sales promotion and helps to stimulate impulse purchasing of product.

- It helps the manufacturer to test the sampling opportunities.

- It supports introduction of new product within retail outlet.

- POPad attractioncreates supportto expand his productsto non-traditionalavenues too

$\circ \quad$ The POP ad helps to build traffic via re-Iaunching the product.

\section{For Retailer:}

- It attracts consumer within retail unit itself.

- It increases his/her interest in shopping and extending the time spent in the store. Effective utilization of floor space available is possible by displaying various products with manufacturer provided material like shelf etc.

- It helps to organize shelf, floor space and improve inventory control, volume, stock turnover better.

- It adds visibility to the sale items which are displayed in the store.

- It helps to solve out of stock problems for seasonal items and helps to cross

$\circ$ merchandise with related items.

\section{For Consumer:}

- It provides information about the product-what is new, what is available and sometimes how it is to be used.

- It simplifies the shopping process for the consumers. Especially simplify the selectionprocess when a similar item is available in the shop.

- It entertains the shoppers through interactive media,TV and Radio which is displaying ad within the store.

\section{POP Advertisement - Points to be kept in Mind:}

"Studies of consumer shopping behaviour have shown that high proportions of all purchase are unplanned, especially in supermarkets, drugstores and mass merchandise outlets." ${ }^{3}$ Mostof the POP advertisement is gaining access in these places. This accessis determined by several factors. If we consider the following points, it can make POP Ad more effective.

\section{Quality of POP material}

Majority of the POP material received by the retailers is secured from the manufacturer (brand makers) free of cost. Such material should attract first the retailer and the consumer with high quality and creativity. If the retailer receives a poor quality material he may be reluctant to use due to poor quality, non-availability of space, or its unsuitable nature. 


\section{Better understanding}

POPAl study (Retailers Attitude on P-O-P 1990) indicates that 90 percent of the retailers are using the same or more point of purchase displays than they used two years ago. So it is good"for the brand makers to have a good relationship and understanding with retailers that precludes the other form of getting shelf or floor space in the retail establishment.

\section{To be supported with other media}

A POP should be coordinated with the theme used in the other media advertisements. This would not only act as a type of repetition; it also creates a last minute association between the campaign and the place of purchase decision.

\section{Better to consult and secure expertise from retailers}

There are estimates that less than one half of all POP materials received by retailers are used. So it is good for ad-agencies/professionals, which are involved in making of such material, to consult retailers for their expertise in this regard.

\section{Ensure and monitor the display of POP Advertisement}

POP ad, which is displayed in the stores, should be monitored and ensured by the brand makers for proper display of material. In case, the retailer has not properly used the material or is wasting it,the brand makers must supplement itwithother promotional methods.

\section{Avail the POP interactive media}

"Today's consumers are educated and they would liketo learn more about the product before buying. These customers also want to spend as littletime as possible when shopping" ${ }^{\text {"I }}$ In such a situation, ifthe retailer uses interactive media, he can overcome shortage of labour, cope with consumer demand and satisfy the demand for greater returns on their in store investments.

\section{POPAdvertisement - Opportunities in India:}

The entry of global brands and the increasing emphasis of Indian companies on POP ad have ensured high delivery standards. The overall approach to POP ad is still largely subjective rather than scientific but the amount spent onthese advertisement is constantly growing.

The Indian POP advertisement industry is currently around RS.1,800 crores growing at a healthy rate of 30 to 40 percent per annum. This growth is going to be fuelled even more as brands decide to spend more money on activities below the line advertisement like POP ad than the traditional above the line advertisement like TV, radio, print because it is becoming less effective in clutter contexts. The companies like Gillette, Colgate, Munch, Himalaya and even regional brands are now becoming POP savvy constantly. It adds new looks to the product in the retail shops.

"According to Business India Jan.3-16, 2005 automobile major Maruti goes for a major signage programme for its dealer outlets and tie-up with Bangalore based retail solution company. The Mahindra \& Mahindra embarks on a new signage programme for its tractor dealer outlets. The Pepsi services have understanding with some six lakhs retail outlets for their point of purchase advertisement. Similarly Britannia services with 8000 retail outlets in Bangalore and HLL too services with 12,000 outlets in Bangalore." ${ }^{5}$

The recently concluded POP Asia 2005 at Mumbai on Feb.20-22 revealed that 98 percent of the retail category in India (small retail) will contribute to the prosperity ofthe POP industry. In order to meet the challenge posed by small outlets with point of purchase advertisement, the bigger behemoths will have to reinvent themselves.

\section{Conclusion}

The future of retail business mainly depends on POP advertisements. The technique used in POP advertisement is continuing to proliferate and reach specific customers, at the regional as well as individual store level. If the POP industry focuses on new ideas, bigger and planned investment and use of new technology, it can harvest great results in the form of good customer base, revenue and profit.

\section{Reference}

[1]. Harish Bijoor: POP is happening and POP ASIA - 2005, Conference Report

[2]. Martin P.David: The Effective use of Advertising Media -A Practical Hand Book

[3]. POPAl's Retailder Attitude on P-O-P, POPAI News, Oct-Nov 1990, p.19

[4]. George F.Bames: Interactive Comes of Age: POPAI News, March-April, 1990, p.8

[5]. Devendra Mohan: Point of Purchase- A Changing Induatry, Business India, Jan.3-16,2005, p.34

Further Reference 
[6]. Alison Fahey: Advertising Media Crowd into Aisles, Advertising Age, 18thJune

[7]. 1990,p.18.

[8]. Devendra Mohan: Point of Purchase -A Changing Industry, Business India, Jan.3-16, and 2005 p.34.

[9]. George F.Bames: Facing the Year Ahead POPAI News, March-April 1990, p.8

[10]. Harish Bijoor: POP is happening and POP ASIA 2005 Conference Report.

[11]. Interactive Comes of Age: POPAI News, March-April 1990, p.18

[12]. P/O/P, The Last word in advertising, A Publication of POPAL P.4-5

[13]. POPAl's Retailer Attitude on P-O-P, POPAI News, Oct-Nov.1990, p.19.

[14]. Martin P.Davis: The Effective use of Adyertising Media-A Practical Hand Book,

[15]. 1988, p.98.

[16]. The Hindu, "When Ads seek New Media", 11th Sep 2003 issue 